\title{
Pengembangan Kurikulum Merujuk KKNI Pada Prodi PIAUD
}

\author{
Sri wahyuni ${ }^{1, *}$, Khadijah ${ }^{2}$, Yusnaili Budianti ${ }^{3}$, Maisarah ${ }^{4}$ \\ 1,2,3 Universitas Islam Negeri Sumatera Utara, Indonesia \\ ${ }^{4}$ Universitas Negeri Medan, Indonesia \\ *sriwahyuni@uinsu.ac.id
}

\begin{abstract}
Abstrak
Pengembangan IPTEKS yang sangat pesat menuntut pemerintah Indonesia melakukan review dalam segala bidang termasuk kurikulum pendidikan. Pemerintah Indonesia telah mencanangkan kurikulum merujuk Kerangka Kualifikasi Nasional Indonesia (KKNI) melalui Perpres No. 08 tahun 2012. Oleh karena itu, penelitian ini bertujuan untuk mengembangkan kurikulum merujuk KKNI pada program studi pendidikan islam anak usia dini (PIAUD) FITK UIN-SU Medan. Jenis penelitian ini merupakan penelitian dan pengembangan model Hannafin \& Peck yang terdiri dari beberapa tahapan, yaitu: analisis kebutuhan, desain, pengembangan, dan implementasi. Teknik pengumpulan data yang digunakan pada penelitian ini yaitu: wawancara terstruktur, dan angket tertutup. Teknik analisis data yang digunakan adalah uji persentase rerata skor. Hasil penelitian ini mengembangkan produk berupa buku kurikulum PIAUD merujuk KKNI yang terbukti sangat valid dan sangat baik untuk digunakan oleh mahasiswa PIAUD. Hal tersebut karena kurikulum yang dikembangkan telah memenuhi unsur KKNI, merujuk KMA 15 tahun 2018, dan mengikuti perkembangan IPTEKS dan dunia kerja di bidang PAUD.
\end{abstract}

Kata Kunci: KKNI; kurikulum PIAUD; KMA 15 tahun 2018

\section{Curriculum Development Referring to KKNI in PIAUD Study Program}

\begin{abstract}
The very rapid development of science and technology demands the Indonesian government to conduct a review in all fields including the educational curriculum. The Indonesian government has launched a curriculum referring to the Indonesian National Qualifications Framework (KKNI) through Presidential Decree No. 08 of 2012. Therefore, this study aims to develop a curriculum referring to KKNI in the Early Childhood Islamic Education (PIAUD) study program, FITK UINSU Medan. This type of research is the research and development of the Hannafin \& Peck model which consists of several stages, namely: needs analysis, design, development, and implementation. The data collection techniques used in this study were: structured interviews and closed questionnaires. The data analysis technique used was the mean score percentage test. The results of this study developed a product in the form of a PIAUD curriculum book referring to KKNI which proved to be very valid and very good for use by PIAUD students. This is because the developed curriculum has fulfilled the elements of KKNI, refers to KMA 15 in 2018, and follows the development of science and technology and the world of work in the PAUD sector.
\end{abstract}

Keywords: Kerangka Kualifikasi Nasional Indonesia (KKNI); curriculum PIAUD, KMA 15 of 2018 


\section{PENDAHULUAN}

Pengembangan Ilmu Pengetahuan dan Teknologi, Seni (IPTEKS) yang sangat pesat menuntut pemerintah Indonesia untuk melakukan review dalam segala bidang kehidupan termasuk review kurikulum pendidikan yang berlaku di Indonesia. Review kurikulum menjadi penting karena merupakan bagian di dalam pendidikan sebagai suatu sistem. (Anggraini, 2014; Anih, 2015; Yusiyaka, 2016) mengemukakan bahwa pendidikan sebagai suatu sistem karena mempunyai beberapa aspek/ komponen/ indikator saling berkaitan yang terdiri dari masukan (input), proses (process), keluaran (output), dan dampak (outcome). Masukan berkaitan dengan sumber daya seperti mahasiswa, dosen, program, dan fasilitas. Proses berkaitan dengan aktivitas, dan penilaian. Keluaran berkaitan dengan lulusan/ kompetensi/ capaian tertentu. Dampak berkaitan dengan produk nyata yang dihasilkan, baik berbasis lokal, nasional, regional maupun internasional. Keempat hal tersebut saling berkaitan satu dan lainnya dan membentuk sebuah sistem di dalam kurikulum.

Pemerintah Indonesia telah mencanangkan kurikulum merujuk Kerangka Kualifikasi Nasional Indonesia (KKNI) melalui Perpres No. 08 tahun 2012. KKNI merupakan perwujudan mutu dan jati diri Bangsa Indonesia terkait dengan sistem pendidikan dan pelatihan nasional yang dimiliki Indonesia. Implementasi KKNI dalam pendidikan tinggi mengharuskan setiap program studi memperjelas profil lulusannya, sehingga dapat disesuaikan dengan kelayakan dalam sudut pandang analisa kebutuhan masyarakat. (Jono, 2016) mengemukakan dalam penelitiannya bahwa Kerangka Kualifikasi Nasional Indonesia (KKNI) adalah kerangka penjenjangan kualifikasi dan kompetensi tenaga kerja Indonesia yang menyandingkan, menyetarakan, dan mengintegrasikan sektor pendidikan dengan sektor pelatihan dan pengalaman kerja dalam suatu skema pengakuan kemampuan kerja yang disesuaikan dengan struktur di berbagai sektor pekerjaan.

Pemerintah sangat serius melakukan perubahan kurikulum pendidikan di Indonesia agar setara dengan pendidikan lain di dunia dengan menggunakan KKNI. Bukti keseriusan ini ditunjukkan dengan banyaknya aturan yang memayungi penerapan kurikulum KKNI. Hasil penelitian (Siagian \& Siregar, 2018) yang mengemukakan bahwa dalam upaya melakukan kualifikasi terhadap lulusan perguruan tinggi di Indonesia, pemerintah telah menerbitkan Perpres No.08 Tahun 2012 tentang Kerangka Kualifikasi Nasional Indonesia (KKNI) dan lampirannya yang menjadi acuan dalam penyusunan capaian pembelajaran lulusan dari setiap jenjang pendidikan secara nasional, yakni juknis Perpres ini Permendikbud no. 73 Tahun 
2013. Terbitnya Perpres No. 08 Tahun 2012 dan UU PT No. 12 Tahun 2012 Pasal 29 ayat (1), (2), dan (3) telah berdampak pada kurikulum dan pengelolaannya di setiap program. Kurikulum yang pada awalnya mengacu pada pencapaian kompetensi menjadi mengacu pada capaian pembelajaran (learning outcomes).

Menurut (Warsah et al., 2020) perubahan kurikulum akan mampu membuat pendidikan di Indonesia menjadi lebih baik lagi, dan perubahan menjadi penyongsong dan penopang laju perkembangan dunia akademik terutama perguran tinggi. Kurikulum merujuk KKNI menuntut lulusan perguruan tinggi memiliki kemampuan sikap, keterampilan kerja, pengetahuan, manajerial, dan tanggung jawab. Sebagaimana dikatakan Megawati Santoso salah seorang Tim KKNI bahwa "Penerapan Kerangka Kualifikasi Nasional Indonesia (KKNI) di Perguruan Tinggi akan menguatkan akuntabilitas penyelenggaraan pendidikan sekaligus menjamin kualitas lulusan”. Kurikulum merujuk KKNI ditujukan memudahkan lulusan perguruan tinggi menghadapi Masyarakat Ekonomi ASEAN (MEA), sebab para lulusan dapat disamakan dengan lulusan dari Universitas di ASEAN. Oleh karena itu, kami mengumpulkan para kepala program studi dan dekan untuk membuat standar kompetensi kelulusan dan capaian pembelajaran.

Penelitian yang dilakukan (Fatoni, 2015) membuktikan bahwa dalam perspektif KKNI, setiap program studi diharuskan memperjelas "profil lulusan" yang diharapkan melalui kegiatan pelacakan studi, studi kelayakan dan analisis kebutuhan di masyarakat. Menurut (Khairiah, 2015; Maslahah, 2018; Nugrahadi et al., 2018) KKNI dilakukan dengan menyusun atau merumuskan beberapa hal, yakni: capaian pembelajaran, profil lulusan program studi, standar kompetensi lulusan, capaian pembelajaran program studi (program learning outcomes/PLO), capaian pembelajaran mata kuliah (course leaning outcomes/CLO), dan pengembangan rencana program dan kegiatan pembelajaran semester (RPKPS). Dengan demikian, upaya meningkatkan kualitas lulusan Perguruan Tinggi, program studi harus melakukan review kurikulum yaitu meliputi: learning outcomes, jumlah sks, mata kuliah wajib, proses pembelajaran yang berpusat pada mahasiswa, akuntabilitas asesmen, waktu studi minimum, dan diploma supplement atau yang dikenal dengan keterampilan pendamping kemampuan mayor lulusan. Namun tidak semua Perguruan Tinggi berhasil menerapkan kurikulum merujuk KKNI yang disebabkan banyak faktor di antaranya; kurangnya pemahaman pengelola progam studi dan dosen tentang KKNI, fasilitas perguruan tinggi yang 
kurang memadai, mutu input mahasiswa, dan dokumen penerapan kurikulum yang belum aplikatif.

UIN Sumatera Utara Medan melalui Keputusan Rektor Nomor 363 Tahun 2015 di dalam (PIU, 2015) telah memberlakukan Kurikulum Merujuk KKNI untuk semua program studi. Keputusan ini mewajibkan semua program studi menyusun dokumen kurikulum merujuk KKNI. Keputusan ini telah diterapkan di Fakultas Ilmu Tarbiyah dan Keguruan pada tahun 2016 dan saat ini semua program telah memiliki buku panduan kurikulum merujuk KKNI. Namun dengan dikeluarkannya Keputusan Menteri Agama Nomor 15 Tahun 2018 tentang Lembaga Pendidikan Tenaga Kependidikan bahwa kurikulum LPTK harus melakukan review kurikulum agar dapat menghasilkan tenaga pendidikan yang berkualitas, maka Fakultas Ilmu Tarbiyah dan Keguruan UIN Sumatera Utara Medan harus segera melakukan kaji ulang terhadap kurikulum yang ada.

Pengkajian ulang mengenai kurikulum yang berlaku pada sebuah program studi sangatlah penting. Sebagaimana penelitian yang dilakukan (Fatoni, 2015) yang mengungkapkan bahwa dalam perspektif KKNI, setiap program studi diharuskan memperjelas profil lulusan yang diharapkan melalui kegiatan pelacakan studi, studi kelayakan dan analisis kebutuhan di masyarakat. Dengan demikian, pengembangan sebuah produk khususnya kurikulum merujuk KKNI bukan hanya mengembangkan kurikulum sesuai dengan kriteria rujukan KKNI, tetapi juga menguji kelayakan (kevalidan) dan keefektifannya (daya guna) kepada subjek yang menerapkan kurikulum. (Akpinar et al., 2017) menyatakan bahwa kurikulum digunakan sebagai petunjuk dan langkah awal dalam proses pembelajaran yang akan diterapkan. Pernyataan tersebut menjadikan pengakjian ulang terhadap kurikulum sangat penting untuk dilakukan. Mengingat pentingnya kaji ulang terhadap kurikulum terutama di program studi pendidikan islam anak usia dini (PIAUD) sebagai salah satu program termuda di FITK, maka perlu dicari model implementasi Kurikulum Merujuk KKNI dan KMA 15 Tahun 2018 di program studi pendidikan islam anak usia dini FITK UIN Sumatera Utara Medan. Dengan demikian dilakukan penelitian dengan judul pengembangan kurikulum merujuk kkni pada prodi PIAUD.

\section{METODE PENELITIAN}

Jenis penelitian yang digunakan dalam penelitian ini adalah metode penelitian dan pengembangan (Research and Development). (Maisarah, 2019a; Sugiyono, 2017) menyatakan 
bahwa metode penelitian pengembangan adalah metode yang digunakan dengan tujuan menghasilkan produk tertentu dengan menguji draft atau kelayakan produk, dan menguji efektivitas produk. Model R\&D yang digunakan pada penelitian ini yaitu model Hannafin \& Peck (Artiniasih et al., 2019; Hannafin \& Peck, 1988; Sinta et al., 2019) yang terdiri dari tiga tahapan, yaitu: (1) analisis kebutuhan, (2) desain, dan (3) pengembangan dan implementasi. Pada ketiga tahapan pengembangan tersebut dilakukan evaluasi dan revisi yang bertujuan agar produk yang dihasilkan lebih baik. Tahapan tersebut secara ringkas disajikan pada gambar 1:

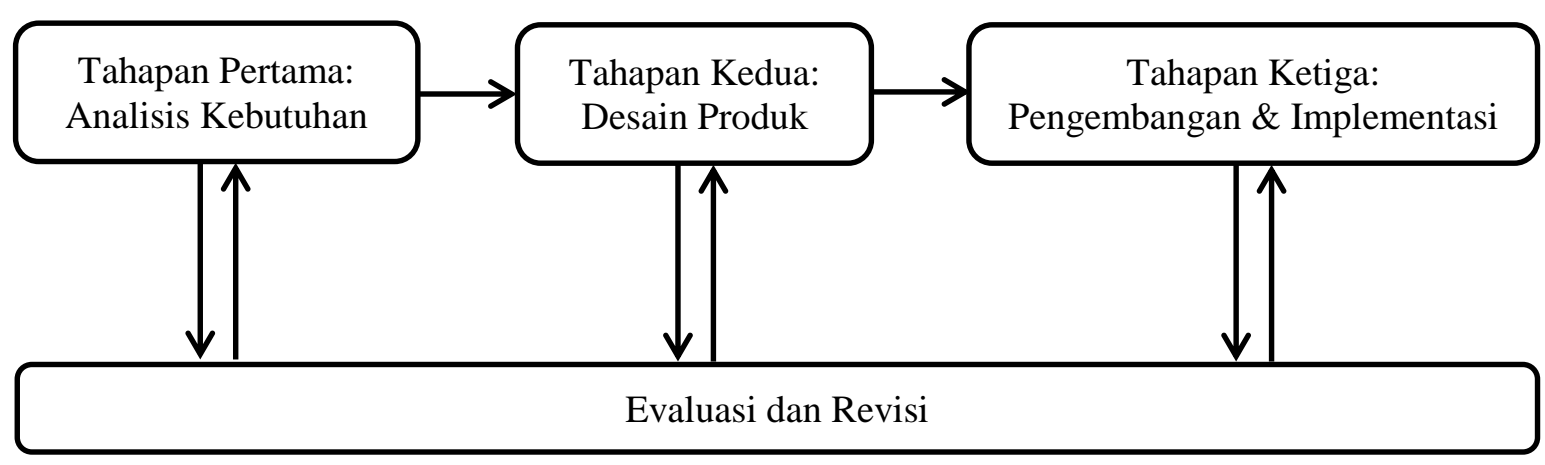

Gambar 1. Diagram Alir Penelitian

Gambar 1 menunjukkan alir penelitian atau proses pengembangan yang dilakukan pada penelitian ini. Pada tahapan pertama (analisis kebutuhan), dilakukan observasi dan wawancara awal untuk menganalisis masalah yang terjadi di sekolah dan mengetahui kebutuhan produk yang dikembangkan melalui penelitian. Pada tahapan kedua (desain produk), dilakukan perancangan draft kurikulum PIAUD berbasis KKNI. Pada tahapan ketiga (pengembangan dan implementasi), dilakukan validasi ahli dan uji lapangan.

Subjek pada penelitian ini terdiri dari beberapa peran, yaitu: (1) ketua prodi PIAUD FITK UINSU Medan; (2) wakil dekan bidang akedemik FITK UINSU Medan; (3) 8 orang dosen PIAUD FITK UINSU Medan; dan (4) 2 orang validator ahli Kurikulum dan 1 orang validator ahli PAUD;. Adapun objek penelitian (produk yang dikembangkan), yaitu: kurikulum PIAUD merujuk KKNI. Instrumen penelitian adalah alat ukur yang digunakan untuk memperoleh data penelitian. Instrumen penelitian yang digunakan yaitu: pedoman wawancara dan lembar angket. Indikator penilaian dari lembar angket yang digunakan untuk memvalidasi produk kurikulum disajikan pada Tabel 1: 
Tabel 1. Indikator Penilaian Validasi Kurikulum PIAUD Berbasis KKNI

\begin{tabular}{|c|c|c|}
\hline $\begin{array}{c}\text { Validator } \\
\text { Ahli }\end{array}$ & Aspek Kurikulum & Kriteria \\
\hline Kurikulum & Khusus & $\begin{array}{l}\text { a. Relevansi } \\
\text { b. Fleksibilitas } \\
\text { c. Kontinuitas } \\
\text { d. Praktis dan efisien } \\
\text { e. Efektivitas } \\
\text { a. Berkenaan dengan tujuan } \\
\text { b. Berkenaan dengan isi pendidikan } \\
\text { c. Berkenaan dengan evaluasi }\end{array}$ \\
\hline $\begin{array}{l}\text { Materi } \\
\text { PIAUD }\end{array}$ & Materi & $\begin{array}{l}\text { a. Kesesuaian kurikulum dengan konsep } \\
\text { PAUD } \\
\text { b. Kemutakhiran materi dan proses } \\
\text { pembelajaran } \\
\text { c. Kontinuitas materi antar tingkat } \\
\text { d. Praktis dan efisien }\end{array}$ \\
\hline
\end{tabular}

Data yang diperoleh dari tabel 1 kemudian dianalisis menggunakan rumus uji persentase rerata skor menurut (Maisarah, 2019b) yaitu: Persentase Rerata Skor (PRS) = $\frac{\text { JumlahSkor }}{\text { SkorMaksimal }}$ 100\%. Kemudian hasil PRS tersebut diklasifikasi berdasarkan Tabel 2:

Tabel 2. Klasifikasi Persentase Rerata Skor

\begin{tabular}{ccc}
\hline Rentang & \multicolumn{2}{c}{ Klasifikasi } \\
\cline { 2 - 3 } & Kevalidan & Keefektifan \\
\hline PRS $>81,25 \%$ & sangat valid & sangat efektif \\
$62,50 \%<$ PRS $\leq 81,25 \%$ & valid & efektif \\
$43,75 \%<$ PRS $\leq 62,50 \%$ & kurang valid & kurang efektif \\
PRS $\leq 43,75 \%$ & tidak valid & tidak efektif \\
\hline
\end{tabular}

Berdasarkan 2 maka disimpulkan bahwa produk yang dikembangkan (kurikulum PIAUD merujuk KKNI) dinyatakan valid dan efektif untuk digunakan apabila memperoleh skor PRS lebih besar dari 62,50\% pada lembar validasi ahli.

\section{HASIL DAN PEMBAHASAN}

\section{A. Hasil}

Mekanisme pelaksanaan perumusan standar isi dan kurikulum prodi PIAUD diperoleh dari hasil wawancara. erdasarkan hasil wawancara dengan Drs Rustam. M.A selaku wakil dekan bidang akedemik, ia mengatakan bahwa: "Dalam perumusan standar isi dan kurikulum setiap prodi khususnya pada prodi PIAUD harus melalui tahapan-tahapan, sehingga 
menghasilkan standar isi dan kurikulum yang terbaik. Tentunya melibatkan orang-orang yang terlibat dalam tanggungjawab ini". Hasil wawancara ini didukung dengan adanya dokumentasi, maka secara rinci ditemukan bahwa perumusan standar isi dan kurikulum prodi PIAUD melalui tiga tahapan, yaitu: (1) perumusan bagian pendahuluan kurikulum yang dilakukan oleh tim pengembang kurikulum dari akademik rektorat di UIN Sumatera Utara Medan; (2) perumusan bagian kurikulum berparadigma interdisipliner dan transdisipliner yang dilakukan oleh tim pengembang kurikulum dan akademik fakultas di FITK UIN Sumatera Utara Medan; dan (3) perumusan bagian profil program studi, capaian pembelajaran, struktur kurikulum, dan sebaran mata kuliah yang dilakukan oleh tim pengembang kurikulum prodi PIAUD FITK UIN Sumatera Utara Medan.

Pengembangan kurikulum merujuk KKNI yang dilakukan pada program studi PIAUD FITK UIN Sumatera Utara Medan dilakukan dengan membuat sebuah produk buku yang berisikan empat bab yang kerangka isinya disajikan pada Tabel 3:

Tabel 3. Daftar Isi Kurikulum PIAUD Berbasis KKNI

\begin{tabular}{|c|c|c|}
\hline Bab ke- & Judul Bab & Judul Sub-Bab \\
\hline I & Pendahuluan & $\begin{array}{l}\text { f. Latar belakang masalah } \\
\text { g. Landasan pengembangan kurikulum } \\
\text { h. Maksud dan tujuan pengembangan } \\
\text { kurikulum }\end{array}$ \\
\hline II & $\begin{array}{l}\text { Kurikulum Berparadigma } \\
\text { Interdisipliner-Transdisipliner }\end{array}$ & $\begin{array}{l}\text { d. Landasan interdisipliner- } \\
\text { trandisipliner ilmu } \\
\text { e. Ranah interdisipliner-trandisipliner } \\
\text { f. Model kajian interdisipliner- } \\
\text { trandisipliner ilmu }\end{array}$ \\
\hline III & $\begin{array}{l}\text { Program Studi Pendidikan Islam } \\
\text { Anak Usia Dini FITK UIN-SU }\end{array}$ & $\begin{array}{l}\text { a. Standar kompetensi lulusan jenjang } \\
\text { strata satu (S1) prodi PIAUD } \\
\text { b. Struktur kurikulum } \\
\text { c. Distribusi mata kuliah } \\
\text { d. Pemetaan bahan kajian, dan beban } \\
\text { belajar } \\
\text { e. Silabus mata kuliah }\end{array}$ \\
\hline IV & Pembelajaran di Prodi PIAUD & $\begin{array}{l}\text { e. Pendekatan dan metode pembelajaran } \\
\text { f. Sistem penilaian pembelajaran } \\
\text { g. Tenaga pendidik (dosen) } \\
\text { h. Sarana dan prasarana pembelajaran } \\
\text { i. Sistem penjamin mutu } \\
\text { j. Contoh rencana pembelajaran } \\
\text { semester (RPS) }\end{array}$ \\
\hline
\end{tabular}


Pengembangan pada produk penelitian ini terjadi pada bab atau bagian ketiga dan keempat di dalam kurikulum, yakni meliputi: standar kompetensi lulusan jenjang strata satu (S1) prodi PIAUD, struktur kurikulum (visi, misi, tujuan, dan kompetensi lulusan), distribusi mata kuliah, pemetaan bahan kajian dan beban belajar, silabus mata kuliah, dan rencana pembelajaran semester (RPS). Pengembangan kurikulum PIAUD merujuk KKNI menghasilkan produk berbentuk buku yang dipublikasi dan mempunyai ISBN. Berikut disajikan cover dan identitas singkat mengenai buku yang disajikan pada gambar 2 dan 3:

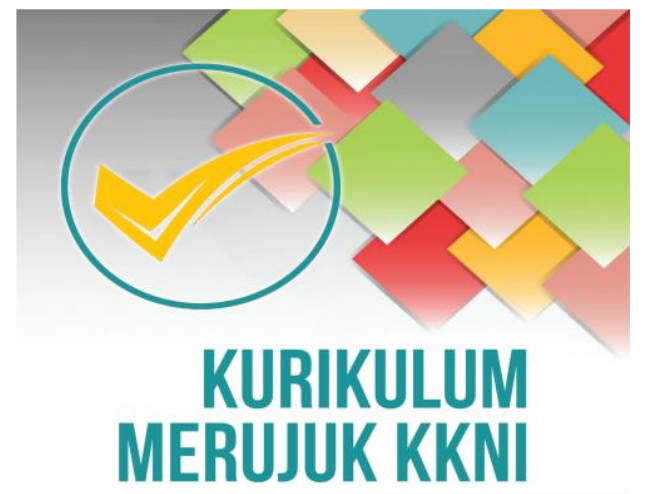

PRODI PENDIDIKAN ISLAM ANAK USIA DINI (PIAUD)

Sri Wahyuni, S.Psi., M.Psi Dr. Yusnaili Budianti, M.Ag

\section{Dpframan}

Gambar 2. Cover Produk Penelitian Kurikulum Merujuk KKNI Prodi PIAUD

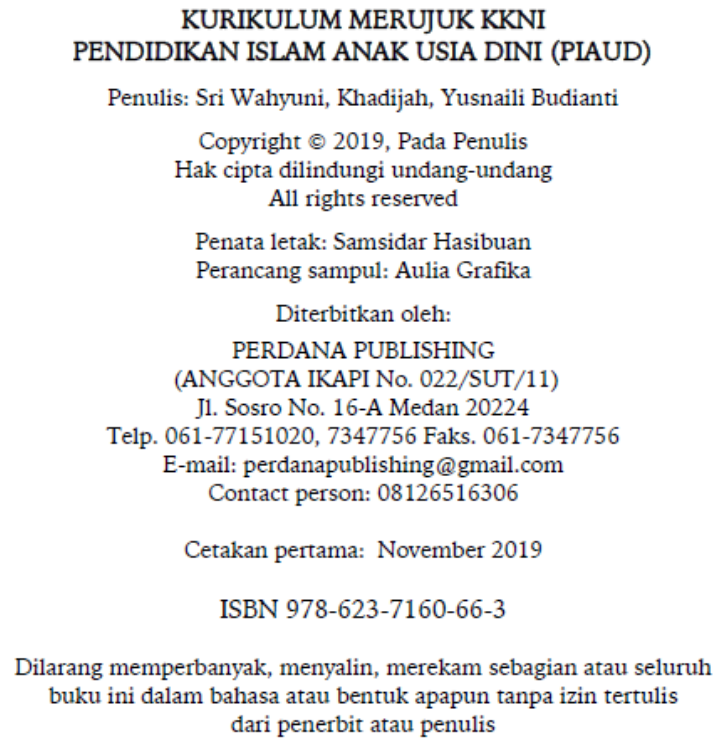

Gambar 3. Identitas Produk Penelitian Kurikulum Merujuk KKNI Prodi PIAUD 
Buku tersebut selanjutnya divalidasi ke beberapa ahli agar didapatkan produk yang layak untuk digunakan pada program studi pendidikan islam anak usia dini (PIAUD) FITK UIN-SU Medan dan dinyatakan sesuai KKNI. Hasil validasi ahli disajikan pada Tabel 4:

Tabel 4. Hasil Validasi Ahli

\begin{tabular}{cccc}
\hline \multirow{2}{*}{ Validator Ahli } & \multicolumn{2}{c}{ Skor Persentase Validasi (\%) } & \multirow{2}{*}{ Kriteria Akhir } \\
\cline { 2 - 3 } & Tahap Awal & Tahap Akhir & \\
\hline Desain kurikulum 1 & 64,44 & 87,78 & Sangat valid \\
Desain kurikulum 2 & 63,33 & 92,22 & Sangat valid \\
Materi PIAUD & 71,67 & 91,67 & Sangat valid \\
\hline Rata-rata & 66,48 & 90,56 & Sangat valid \\
\hline
\end{tabular}

Validasi ahli desain kurikulum menilai dua aspek kurikulum, yakni: (1) aspek umum yang terdiri dari lima kriteria yaitu: relevansi, fleksibilitas, kontinuitas, praktis dan efisien, dan efektivitas; (2) aspek umum yang terdiri dari tiga kriteria yaitu: berkenaan dengan tujuan, berkenaan dengan isi pendidikan, dan berkenaan dengan evaluasi. Validator ahli desain kurikulum 1 memberikan skor persentase sebesar 64,44\% pada tahap validasi awal dan 87,78\% pada tahap validasi akhir. Validator ahli desain kurikulum 2 memberikan skor persentase sebesar 63,33\% pada tahap validasi awal dan 92,22\% pada tahap validasi akhir. Penilaian akhir dari dua orang validator ahli desain kurikulum mempunyai kategori sangat valid karena skor lebih dari 81,25\%, sehingga terbukti bahwa kurikulum PIAUD yang dikembangkan sudah memenuhi Kurikulum Perguruan Tinggi (KPT) yang merujuk KKNI.

Saran perbaikan dari validator ahli desain kurikulum juga sejalan dengan panduan pengembangan kurikulum PTKI mengacu pada (Peraturan Menteri Pendidikan dan Kebudayaan Nomor 49 Tahun 2014 tentang Standar Nasional Pendidikan Tinggi, 2014; Peraturan Kementerian Riset, Teknologi, dan Pendidikan Tinggi Nomor 44 Tahun 2015 tentang Standar Nasional Pendidikan Tinggi, 2015) yang menyatakan bahwa penyusunan kurikulum yang dilakukan oleh pengelola program studi terdiri dari 9 tahapan, yaitu: (1) penetapan profil lulusan; (2) penetapan capaian pembelajaran lulusan (CPL); (3) penetapan bahan kajian; (4) penetapan mata kuliah; (5) penetapan besaran SKS mata kuliah; (6) penyusunan struktur kurikulum; (7) proses pembelajaran; (8) penilaian; dan (9)penyusunan Rencana Pembelajaran Semester. Sehingga pada proses validasi diberikan saran berupa: (1) penambahan matriks peta keilmuan dan bahan kajian untuk; (2) penambahan proses pembelajaran di prodi PIAUD FITK UIN-SU Medan yang berisikan tentang proses dan penilaian. 
Validasi ahli materi PIAUD menilai produk kurikulum berdasarkan empat kriteria, yaitu: (1) kesesuaian dengan konsep dan praktek PAUD; (2) kemutakhiran; (3) kontinuitas; dan (4) praktis serta efisien. Validator ahli materi PIAUD memberikan skor persentase sebesar 71,67\% pada tahap validasi awal dan 91,67\% pada tahap validasi akhir. Penilaian akhir dari validator ahli materi PIAUD mempunyai kategori sangat valid karena skor lebih dari $81,25 \%$, sehingga terbukti bahwa kurikulum PIAUD yang dikembangkan sudah memenuhi Kurikulum Perguruan Tinggi (KPT) yang merujuk KKNI, bahkan materi di dalam kurikulum terbukti sangat layak diterapkan pada prodi PIAUD. Hal tersebut terlihat dari beberapa komponen kurikulum, yaitu: (1) profil lulusan sesuai dengan PIAUD dan kebutuhan masyarakat yaitu pendidik, peneliti pemula, dan perancang alat bermain AUD; (2) CPL juga sesuai dengan deskripsi kualifikasi level 6 jenjalng sarjana dan bidang kekhususan program studi PIAUD; (3) bahan kajian dibuat dalam bentuk matriks (pemetaan) sehingga terlihat bahan kajian (mata kuliah) sesuai CPL; (4) mata kuliah, beban belajar dan distribusi dilakukan bukan hanya berdasarkan jenis pengelompokan mata kuliah, tetapi juga memperhatikan beberapa mata kuliah yang menjadi prasyarat mata kuliah lainnya dan jumlah sks setiap semester, sehingga mata kuliah pada setiap semester saling berkaitan dan semakin tinggi konsep PAUD yang diajarkan; (5) struktur kurikulum berisikan tentang visi, misi, tujuan dan kompetensi lulusan yang telah disesuaikan dengan target dan bidang keilmuan Pendidikan Islam Anak Usia Dini; (6) proses dan penilaian pembelajaran berdasarkan pada strategi perkuliahan yang telah ditetapkan oleh bidang akademik FITK UIN-SU Medan dan tugas-tugasnya disesuaikan dengan profil lulusan, CPL, serta struktur kurikulum PIAUD; dan (7) pada Rencana Perkuliahan Semester juga terlihat materi-materi yang diajarkan tidak terlepas dari bidang keilmuan PIAUD dan rumusan CPL prodi PIAUD. Dari uraian tersebut terbuktilah bahwa kevalidan dari ahli bukan sekedar penilaian tetapi juga berdasarkan bukti dokumen kurikulum yang disajikan pada Lampiran.

Selanjutnya hasil uji coba lapangan membuktikan bahwa kurikulum PIAUD merujuk KKNI efektif ketika diterapkan di kelas PIAUD 1 semester I, III, V, dan VII. Pada semester I dilakukan uji coba untuk mata kuliah Bahasa Indonesia, pada semester III dilakukan uji coba untuk mata kuliah pengembangan kognitif AUD, pada semester V dilakukan uji coba untuk mata kuliah pengembangan kreativitas AUD, dan pada semester VII dilakukan uji coba untuk mata kuliah pengembangan kecerdasan majemuk (multiple intelegences). Uji coba dilakukan pada pertemuan keempat dengan menerapkan RPS yang terdapat di dalam produk kurikulum 
berbasis KKNI dan angket tanggapan dosen mengenai proses pembelajaran dari mata kuliah yang diujicobakan. Untuk materi mata kuliah tidak ada perbedaan antara kurikulum lama dengan kurikulum PIAUD merujuk KKNI, karena perubahan yang terjadi hanya pada CPL, proses dan penilaian mata kuliah yang lebih mengutamakan keaktifan mahasiswa. Hasil angket respon dosen disajikan pada Tabel 5:

Tabel 5. Hasil Angket Respon Dosen

\begin{tabular}{|c|c|c|}
\hline No & Pernyataan & Skor \\
\hline 1 & $\begin{array}{l}\text { Penggunaan kurikulum PIAUD memudahkan dosen untuk merumuskan } \\
\text { capaian matakuliah }\end{array}$ & 8 \\
\hline 2 & $\begin{array}{l}\text { Penggunaan kurikulum PIAUD memudahkan dosen untuk } \\
\text { mengintegrasikan beberapa mata kuliah yang saling berkaitan }\end{array}$ & 8 \\
\hline 3 & $\begin{array}{l}\text { Penggunaan kurikulum PIAUD memudahkan dosen untuk menentukan } \\
\text { kemampuan akhir mahasiswa yang harus dicapai sesuai profil lulusan }\end{array}$ & 8 \\
\hline 4 & $\begin{array}{l}\text { Penggunaan kurikulum PIAUD memudahkan dosen untuk menentukan } \\
\text { kemampuan akhir mahasiswa yang harus dicapai mengikuti tuntutan } \\
\text { Revolusi Industri } 4.0\end{array}$ & 8 \\
\hline 5 & $\begin{array}{l}\text { Penggunaan kurikulum PIAUD memudahkan dosen untuk menyusun } \\
\text { bahan kajian berazaskan nilai-nilai IMTAQ }\end{array}$ & 4 \\
\hline 6 & $\begin{array}{l}\text { Penggunaan kurikulum PIAUD memudahkan dosen untuk menentukan } \\
\text { bentuk pembelajaran sesuai perkembangan IPTEK }\end{array}$ & 8 \\
\hline 7 & $\begin{array}{l}\text { Penggunaan kurikulum PIAUD memudahkan dosen untuk menentukan } \\
\text { pengalaman belajar mahasiswa sesuai kemampuan akhir dan kriteria } \\
\text { instrumen }\end{array}$ & 8 \\
\hline 8 & $\begin{array}{l}\text { Penggunaan kurikulum PIAUD memudahkan dosen untuk menyusun } \\
\text { instrumen penilaian sesuai tuntutan KKNI (tugas rutin, critical book } \\
\text { report, critical book review, rekayasa ide, project, dan mini riset) }\end{array}$ & 7 \\
\hline 9 & $\begin{array}{l}\text { Penggunaan kurikulum PIAUD menjadi panduan dosen dalam menyusun } \\
\text { RPS dan Silabus }\end{array}$ & 8 \\
\hline \multirow[t]{4}{*}{10} & $\begin{array}{l}\text { Penggunaan kurikulum PIAUD menjadi panduan dosen dalam } \\
\text { melaksanakan perkuliahan }\end{array}$ & 8 \\
\hline & Jumlah & 75 \\
\hline & Persentase $(\%)$ & 93,75 \\
\hline & Kriteria & Sangat Baik \\
\hline
\end{tabular}

Tabel 5 menunjukkan perolehan skor persentase respon dosen yaitu sebesar 93,75\% dan mempunyai kriteria sangat baik. Respon yang sangat baik dari dosen pengampu membuktikan bahwa kurikulum merujuk KKNI mempunyai kriteria sangat efektif untuk digunakan pada berbagai mata kuliah interdisipliner-transdisipliner di program studi Pendidikan Islam Anak Usia Dini (PIAUD) FITK UIN Sumatera Utara Medan. Bahkan beberapa dosen yang mengisi angket meminta RPS yang disajikan di dalam produk penelitian untuk mereka gunakan pada pertemuan selanjutnya hingga akhir perkuliahan. Hal tersebut 
karena RPS di dalam produk lebih komplit dibandingkan dengan RPS yang biasa mereka gunakan, khususnya mengenai penilaian autentik yang sesuai KKNI (tugas rutin, critical book report, critical book review, rekayasa ide, project, dan mini riset), beserta aktivitas dan capaiannya.

\section{B. Pembahasan}

Penelitian ini menghasilkan produk berupa buku kurikulum PIAUD merujuk KKNI. Pengembangan pada produk penelitian ini dilakukan pada bab atau bagian ketiga dan keempat di dalam kurikulum (Tabel 3) yang meliputi: standar kompetensi lulusan jenjang strata satu (S1) prodi PIAUD, struktur kurikulum (visi, misi, tujuan, dan kompetensi lulusan), distribusi mata kuliah, pemetaan bahan kajian dan beban belajar, silabus mata kuliah, dan rencana pembelajaran semester (RPS). Hasil validasi ahli dan respon dosen membuktikan bahwa kurikulum PIAUD yang dikembangkan memenuhi Kurikulum Perguruan Tinggi (KPT) merujuk KKNI, sangat layak untuk digunakan pada program studi PIAUD, dan mendapatkan respon yang sangat baik dari dosen pengampu beberapa mata kuliah. Dengan kata lain, penelitian ini bukan sekedar menghasilkan sebuah produk kurikulum yang merujuk KKNI tetapi juga membuktikan kelayakan dan keefektifannya di dalam proses perkuliahan.

Pengembangan ini merujuk pada beberapa hasil penelitian terdahulu yang juga membahas mengenai kurikulum, baik berbasis KKNI maupun fitur di dalam kurikulum pada umumnya, yaitu: hasil penelitian (Oliver et al., 2008) memberikan rekomendasi agar kurikulum mempunyai beberapa fitur berikut: berbasis kompetensi dan hasil, berpusat pada siswa, belajar dalam konteks dan dalam tindakan, integrasi subjek secara horizontal dan vertikal, pembelajaran dan pengajaran klinis yang berpusat pada pasien, penggunaan bukti terbaik untuk menginformasikan praktik terbaik, penilaian formatif dan sumatif eksplisit dengan umpan balik konstruktif yang teratur, dan penggunaan pilihan atau proyek penelitian untuk memfasilitasi semangat penyelidikan dan / atau mobilitas.

Menurut (Khairiah, 2015; Maslahah, 2018; Nugrahadi et al., 2018) KKNI dilakukan dengan menyusun atau merumuskan beberapa hal, yakni: capaian pembelajaran, profil lulusan program studi, standar kompetensi lulusan, capaian pembelajaran program studi (program learning outcomes/PLO), capaian pembelajaran mata kuliah (course leaning outcomes/CLO), dan pengembangan rencana program dan kegiatan pembelajaran semester (RPKPS). Perbedaan antara penelitian ini dengan penelitian terdahulu yaitu: pada penelitian ini 
mengembangkan kurikulum pada program studi PIAUD berbasis KKNI, dan pengembangan bukan hanya dilakukan pada RPS tetapi juga pada silabus pembelajaran.

Pengembangan dilakukan bukan hanya karena anjuran pemerintah mengenai KKNI tetapi juga berdasarkan karena mengikuti perkembangan zaman dan kebutuhan masyarakat. Oleh sebab itu, kurikulum sebagai pedoman pendidikan harus mensinkronisasi antar teori dan praktik. (Maba, 2016) mengemukakan bahwa kurikulum sarjana berbasis KKNI merupakan kombinasi antara pola pikir deduktif (teori di kampus) dengan pola pikir induktif (praktik di lapangan). (Sudrajat, 2018) menambahkan bahwa kurikulum yang baik disusun oleh pendidik dan pengguna lulusan yang berisi hal-hal yang solid, tetapi dalam prelaksanaannya memungkinkan terjadinya penyesuaian-penyesuaian berdasarkan kondisi daerah, waktu maupun kemampuan/ kompetensi dan latar belakang mahasiswa.

Menurut (Nurhadi \& Setiyawan, 2017) kaitan antara kurikulum dengan lulusan yakni: lulusan harus memiliki standar kompetensi lulusan yang dapat dimanfaatkan dan relevan dengan lapangan kerja yang tersedia, sehingga lulusan tersebut memiliki daya saing tinggi dan luas dalam menghadapi dunia kerja baik secara nasional maupun internasional. Sehingga perumusan lulusan harus jelas tergambar pada kurikulum agar pembelajaran menjadi terarah. (Nurdin, 2018) penerapan KKNI (Peraturan Presiden No. 8 Tahun 2012 tentang KKNI) dalam kurikulum perlu merumuskan learning outcomes, yaitu menggambarkan secara jelas dan spesifik postur/sosok lulusan yang akan dihasilkan. (Nurhadi \& Setiyawan, 2017) PBA UIN Malang mengimplementasikan kurikulum dengan mensinkronisasi 3 hal penting di dalam KKNI yakni: rumusan profil, capaian pembelajaran dan pengelolaan pembelajaran. Dengan dirumuskannya profil dan kompetensi lulusan yang jelas sesuai dengan program studi yakni pendidikan Islam anak usia dini maka selanjutnya ditentukan pedoman capaian dan proses pembelajaran. (Haris, 2019) Perubahan mendasar mengenai capaian pembelajaran minimal berbasis KKNI meliputi; (i) learning to know, (ii) learning to do, (iii) learning to live together (with others), dan (iv) learning to be, serta; belajar sepanjang hayat (learning throughout life). Capaian pembelajaran lulusan (CPL) sebagai Learning outcomes (LO) disusun meliputi bidang sikap dan nilai, keterampilan umum (mengacu pada rumusan yang telah ditetapkan dalam SN-Dikti), dan pengetahuan, keterampilan khusus (sesuai jenjang kualifikasi KKNI). Dengan demikian, pengembangan atau revitalisasi kurikulum harus dilakukan dalam jangka waktu atau periode tertentu, dan memperimbangkan lulusan program studi yang diharapkan sehingga proses pendidikan di program studi tersebut terarah dan tujuannya dapat tercapai. 
Hasil penelitian (Rosnah et al., 2018) menunjukkan bahwa pengembangan pembelajaran IPS berbentuk buku yang hasil pengembangannya terbukti sangat valid dan layak digunakan pada mata kuliah ilmu sosial. Temuan lain dari penelitian adalah produk dapat membantu dosen dalam mengembangkan keteramilan sosial mahasiswa, seperti (1) komunikasi lisan; (2) kerja sama; (3) pengendalian emosi; (4) mengelola konflik; dan (5) menentukan keputusan. Dari penelitian Rosnah maka dapat ditarik kesimpulan bahwa setiap produk yang dihasilkan harus dinyatakan valid agar layak untuk digunakan, selain itu produk juga harus mempunyai daya guna khususnya pada saat pelaksanaan penelitian maupun setelah produk resmi diterapkan. Penelitian yang dilakukan (Fatoni, 2015) bahwa dalam perspektif KKNI, setiap program studi diharuskan memperjelas "profil lulusan” yang diharapkan melalui kegiatan pelacakan studi, studi kelayakan dan analisis kebutuhan di masyarakat. Dengan demikian, pengembangan sebuah produk khususnya kurikulum merujuk KKNI bukan hanya mengembangkan kurikulum sesuai dengan kriteria rujukan KKNI, tetapi juga menguji kelayakan (kevalidan) dan keefektifannya (daya guna) kepada subjek yang menerapkan kurikulum. (Akpinar et al., 2017) mengemukakan bahwa kurikulum digunakan sebagai petunjuk dan langkah awal dalam proses pembelajaran yang akan diterapkan dalam proses pembelajaran.

Dari uraian di atas membuktikan bahwa pengembangan kurikulum sangat penting untuk dilakukan karena kurikulum merupakan acuan atau pedoman pelakasanaan sebuah lembaga pendidikan, setiap pengembangan kurikulum harus merujuk profil lulusan yang diharapkan oleh komunitas dan kebutuhan masyarakat, setiap pengembangan kurikulum juga harus diuji kelayakan dan keefektivannya sehingga jelas hasil dari pengembangan bukan hanya berbentuk produk tetapi manfaat dari aplikasi produk.

\section{SIMPULAN DAN SARAN}

Hasil penelitian menunjukkan bahwa produk yang dihasilkan berupa buku kurikulum PIAUD merujuk KKNI dan sesuai dengan KMA 15 Tahun 2018. Buku kurikulum PIAUD merujuk KKNI yang dikembangkan terbukti sangat valid dan sangat baik untuk digunakan oleh mahasiswa PIAUD. Kurikulum menganut aliran progresivisme yang berarti terjadi proses perubahan secara terus menerus mengikuti perkembangan IPTEKS di lapangan sehingga dibutuhkan revitalisasi dan pengembangan kurikulum secara periodik agar lulusan yang dihasilkan prodi dapat berkontribusi nyata di dunia kerja dan pendidikan. Oleh karena 
itu, penelitian ini diharapkan dapat menjadi referensi untuk melakukan pengembangan kurikulum maupun untuk membuat kebijakan akademik yang berkaitan dengan kurikulum.

\section{UCAPAN TERIMA KASIH}

Tim peneliti menyampaikan ucapan terima kasih kepada DIPA Direktorat Jenderal Pendidikan Islam di Indonesia karena telah memberikan izin dan mendanai penelitian ini. Terima kasih kepada LP2M UIN-SU Medan karena telah memfasilitasi proses hingga penyelesaian laporan penelitian. Terima kasih juga disampaikan kepada ketua, sekretaris, staf dan dosen program studi PIAUD yang turut mengambil andil di dalam perancangan, proses, pelaporan penelitian hingga penulisan artikel dari penelitian yang telah dilakukan. Besar harapan artikel ini dapat memberikan manfaat bagi para pembaca.

\section{DAFTAR PUSTAKA}

Akpinar, B., Batdı, V., Özeren, E., \& Kirilmazkaya, G. (2017). The Meaning Crisis of Curriculum in Information Age. International Journal of Information and Education Technology, 7(9), 661-664. https://doi.org/0.18178/ijiet.2017.7.9.949

Anggraini, H. G. (2014). Analisi Output dan Outcome Bidang Pendidikan. Jurnal Pendidikan Ekonomi Dinamika Pendidikan, IX(1), 70-82. https://doi.org/https://doi.org/10.15294/dp.v9i1.3357

Anih, E. (2015). Manajemen Implementasi Kebijakan Pengambangan Kurikulum di Perguruan Tinggi Berbasis Kompetensi. Jurnal Pendidikan Unsika, 3(1), 1-21.

Artiniasih, N. K. S., Agung, A. A. G., \& Sudatha, I. G. W. (2019). Pengembangan Elektronik Modul Berbasis Proyek Mata Pelajaran Ilmu Pengetahuan Alam Kelas VIII Sekolah Menengah Pertama. Jurnal Edutech Universitas Pendidikan Ganesha, 7(1), 54-65. https://doi.org/10.23887/jeu.v7i1.20008

Fatoni, A. (2015). Manajemen Pengembangan Kurikulum Berbasis KKNI. Al-Idarah: Jurnal Kependidikan Islam, 5(1), 76-91. https://doi.org/10.24042/alidarah.v5i1.755

Hannafin, M. J., \& Peck, K. L. (1988). The Design, Development, and Evaluation of. Instructional Software. New York: Macmillan Publishing Company.

Haris, A. (2019). Penerapan Kurikulum Berbasis KKNI Pada Program Studi Pendidikan Agama Islam. Al-Furqan: Jurnal Studi Pendidikan Islam, VII(2), 63-81.

Jono, A. A. (2016). Studi Implementasi Kurikulum Berbasis KKNI Pada Program Studi Pendidikan Bahasa Inggris di LPTK Se-Kota Bengkulu. Jurnal Manhaj, 4(1), 57-68. https://doi.org/http://dx.doi.org/10.1161/mhj.v4i1.148.g136

Peraturan Menteri Pendidikan dan Kebudayaan Nomor 49 Tahun 2014 tentang Standar Nasional Pendidikan Tinggi, (2014). 
Peraturan Kementerian Riset, Teknologi, dan Pendidikan Tinggi Nomor 44 Tahun 2015 tentang Standar Nasional Pendidikan Tinggi, (2015).

Khairiah. (2015). Pengaruh Implementasi Kurikulum Berbasis KKNI Terhadap Peningkatan Mutu Pendidikan PTAIN. Jurnal Nuansa, VIII(2), 171-184. https://doi.org/10.29300/nuansa.v8i2.395

Maba, W. (2016). Kurikulum Sarjana Berbasis KKNI Mengubah Mindset Pengajaran Menjadi Pembelajaran. Jurnal Bakti Saraswati, 5(1), 85-87.

Maisarah. (2019a). Metodologi Penelitian Pendidikan Pendekatan Kuantitatif. Medan: Akasha Sakti.

Maisarah. (2019b). Statistik Pendidikan. Medan: Akasha Sakti.

Maslahah, A. U. (2018). Penerapan Kurikulum Mengacu KKNI dan Implikasinya Terhadap Kualitas Pendidikan di PTKIN. Edukasia: Jurnal Penelitian Pendidikan Islam, 13(1), 227-248. https://doi.org/10.21043/edukasia.v13i1.5717

Nugrahadi, E. W., Maipita, I., Ane, L., \& Putra, P. D. (2018). Analisis Implementasi Kurikulum Berbasis KKNI di Fakultas Ekonomi UNIMED. Jurnal Niagawan, 7(1), 8 13. https://doi.org/10.24114/niaga.v7i1.9349

Nurdin, H. S. (2018). Pengembangan Kurikulum dan Rencana Pembelajaran Semester (RPS) Berbasis KKNI di Perguruan Tinggi. Jurnal Al-Ashlah, 2(1), 21-30. https://doi.org/10.31958/jaf.v5i1.813

Nurhadi, \& Setiyawan, A. (2017). Model Penerapan Kerangka Kualifikasi Nasional Indonesia (KKNI) Sebagai Penguatan Mutu Program Studi Pendidikan Bahasa Arab. al Mahāra Jurnal Pendidikan Bahasa Arab, 3(2), 219-238. https://doi.org/10.14421/almahara.2017.032-02

Oliver, R., Kersten, H., Vinkka-Puhakka, H., Alpasan, G., Bearng, D., Cema, I., Delap, E., Dummer, P., Goulet, J. P., Gugushen, T., Jeniati, E., Jerolimov, V., Kotasnos, N., Krifka, S., Levy, G., Neway, M., Ogawan, T., Saag, M., Sidlauskas, A., ... White, D. (2008). Curriculum Strukture: Principles and Strategy. European Journal of Dental Education, 12(1). https://doi.org/10.1111/j.1600-0579.2007.00482.x

PIU, P. A. (2015). Buku Pedoman Pengembangan Kurikulum Universitas Islam Negeri Tahun 2015. Medan: Universitas Islam Negeri Sumatera Utara Medan.

Rosnah, S., Setiawan, D., \& Hadiningrum, S. (2018). The Development of Social Studies Learning based on the Local Wisdom to Improve Students' Social Skills at Social Science Faculty of Universitas Negeri Medan. Advances in Social Science, Education and Humanities Research (ASSEHR), 208(1). https://doi.org/10.2991/icssis-18.2019.71

Siagian, B. A., \& Siregar, G. N. S. (2018). Analisis Penerapan Kurikulum Berbasis KKNI di Universitas Negeri Medan. PEDAGOGIA : Jurnal Ilmu Pendidikan, 16(3), 327-342. https://doi.org/10.17509/pdgia.v16i3.12378

Sinta, M. D., Alfianda, \& Waluyati, S. A. (2019). Pengembangan Media Pembelajaran Mobile Learning Berbasis Masalah Dalam Pembelajaran PPKn di SMA. Bhineka Tunggal Ika: Kajian Teori dan Praktik PKn, 6(2), 224-231. https://doi.org/10.36706/jbti.v6i2.8713 
Sudrajat, D. (2018). Kurikulum Pendidikan Bahasa Inggris Berbasis KKNI: Prosedur Pengembangan dan Implementasinya. Jurnal Intelegensia, 3(1), 14-30.

Sugiyono. (2017). Metode Penelitian Pendidikan Pendekatan Kuantitatif, Kualitattif dan $R n D$. Bandung: Alfabeta.

Warsah, I., Imron, Siswanto, \& Sendi, O. A. M. (2020). Strategi Implementatif KKNI dalam Pembelajaran Pendidikan Islam di IAIN Curup. Jurnal Tarbiyatuna, 11(1), 77-90. https://doi.org/10.31603/tarbiyatuna.v11i1.3442 Article

Yusiyaka, R. A. (2016). Penilaian (Evaluating) Pada Program Pendidikan Luar Sekolah. Journal Educate, 1(1), 49-58. https://doi.org/10.32832/educate.v1i1.418 